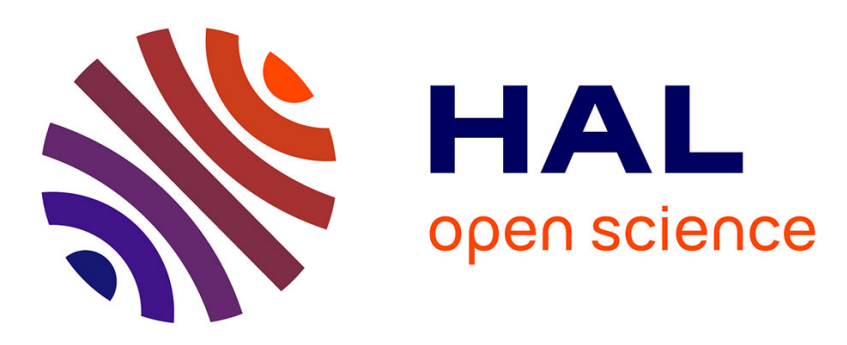

\title{
The use of hyperspectral imagery for digital soil mapping in mediterranean areas
}

Philippe Lagacherie, Cécile Gomez, Jean-Stéphane Bailly, Frédéric Baret, Guillaume Coulouma

\section{- To cite this version:}

Philippe Lagacherie, Cécile Gomez, Jean-Stéphane Bailly, Frédéric Baret, Guillaume Coulouma. The use of hyperspectral imagery for digital soil mapping in mediterranean areas. Digital Soil Mapping, 2, Springer Netherlands, 435 p., 2010, Progress in Soil Science, 978-90-481-8863-5. 10.1007/978-90481-8863-5_8. hal-01137201

\section{HAL Id: hal-01137201 \\ https://hal.science/hal-01137201}

Submitted on 30 Mar 2015

HAL is a multi-disciplinary open access archive for the deposit and dissemination of scientific research documents, whether they are published or not. The documents may come from teaching and research institutions in France or abroad, or from public or private research centers.
L'archive ouverte pluridisciplinaire HAL, est destinée au dépôt et à la diffusion de documents scientifiques de niveau recherche, publiés ou non, émanant des établissements d'enseignement et de recherche français ou étrangers, des laboratoires publics ou privés. 


\title{
Chapter 8 \\ The Use of Hyperspectral Imagery for Digital Soil Mapping in Mediterranean Areas
}

\author{
P. Lagacherie, C. Gomez, J.S. Bailly, F. Baret, and G. Coulouma
}

\begin{abstract}
Hyperspectral imagery is considered as a promising source of data to overcome the lack of soil information that often hamper digital soil mapping. We have tested it in the vineyard plain of Languedoc (southern France) using an $5 \times 5 \mathrm{~m}$ resolution HYMAP image and 52 calibration-validation points. Satisfactory predictions of clay content and calcium carbonate $\left(\mathrm{CaCO}_{3}\right)$ content were first obtained from HYMAP spectra over bare soils, partial least-squares regression performing better than continuum removal technique. These predictions were however less precise than using laboratory spectra. An examination of the possible factors that could explain this decrease showed that calibration uncertainties of the HYMAP sensor and of atmospheric effects were largely predominant. Secondly, since the HYMAP image was largely covered by vegetation with few pure bare soil pixels, an interpolation-aggregation procedure was proposed to obtain a $100 \times 100 \mathrm{~m} \mathrm{dig-}$ ital soil map of the whole study area from a set of scattered bare soil fields with hyperspectral soil characterization. Interpolation was performed by a conditional simulation algorithm to estimate the within pixel soil pattern parameters. Validation results showed that satisfactory estimates of local means can be obtained whereas the variations of local variances were only partly represented.

In the near future, a new proof-of-concept zone will be implemented in Tunisia to confirm these encouraging results and to examine how hyperspectral imagery can be used in association with soil legacy data and digital terrain models to produce digital maps of soil properties in the Mediterranean areas.
\end{abstract}

Keywords Remote sensing - Reflectance spectroscopy - Partial least square regression · Uncertainty · Upscaling

P. Lagacherie $(\otimes)$

INRA Laboratoire d'étude des Interactions Sol Agrosystème Hydrosystème (LISAH), UMR 1221

INRA-IRD-Supagro Montpellier, Montpellier, France

e-mail: lagache@supagro.inra.fr

J.L. Boettinger et al. (eds.), Digital Soil Mapping, Progress in Soil Science 2, 


\subsection{Introduction}

It has been largely recognized in the previous digital soil mapping workshops (Lagacherie, 2008) that poor soil datasets have been (and still remain) a factor that can severely limit digital soil mapping progress. It is thus important to include the use of soil sensors that can deliver precise soil property estimates over large areas in the digital soil mapping toolbox. Among the large set of possible soil sensors, visible and near infrared (vis-NIR) hyperspectral imagery is one of the most promising candidates since it is derived from reflectance spectroscopy, a laboratory technique that was proved as being a good alternative to the costly soil physical and chemical laboratory analysis for the estimation of a large range of soil properties (Viscarra Rossel et al., 2006; see also Section 7.2.3), and the few studies that exist in the literature show promising results (e.g., Ben-Dor et al., 2008; Gomez et al., 2008b). It is important to note that hyperspectral imagery can estimate the properties of the immediate soil surface only (e.g., the first millimetres). However, it provides a new soil covariate layer that may serve to estimate soil properties of deeper soil layers and to predict soil classes.

Hyperspectral imagery looks particularly promising in Mediterrancan areas where bare soil surfaces and dry soil conditions are frequent, easing the interpretation of hyperspectral images. This is why our research team was early to work (since 2003) on hyperspectral imagery. The first exploratory results were presented in the first digital soil mapping workshop in Montpellier, France in 2004 (Madeira et al., 2007). Since then, further research has been undertaken on three questions that must be addressed for an effective use of hyperspectral imagery in digital soil mapping: (i) How to derive soil property estimates from Vis-NIR spectra? (Gomez et al., 2008a; Lagacherie et al., 2008), (ii) what are the main perturbing factors when passing from laboratory to remote sensing spectra? (Lagacheric et al., 2008), and (iii) how to obtain a digital soil map from a hyperspectral image with high fraction of pixels covered by the vegetation?

This paper summarizes the main findings of the research listed above.

\subsection{The "Peyne Experiment"}

\subsubsection{Study Area}

The study was carried out in la Peyne catchment, South of France $\left(43^{\circ} 29^{\prime} \mathrm{N}\right.$ and $3^{\circ} 22^{\prime}$ E) (Fig. 8.1), which is dominated by vineyard land cover. Marl, limestone and calcareous sandstones coming from Miocene marine and lacustrine sediments (Fig. 8.2) formed the parent material of several soil types observed in this area: Lithic Leptosols, Calcaric Regosols and Calcaric Cambisols. These sediments were partly covered by successive alluvial deposits ranging from the Pliocene to Holocene and differing in their initial nature and in the duration of weathering 
Fig. 8.1 Location of the study area

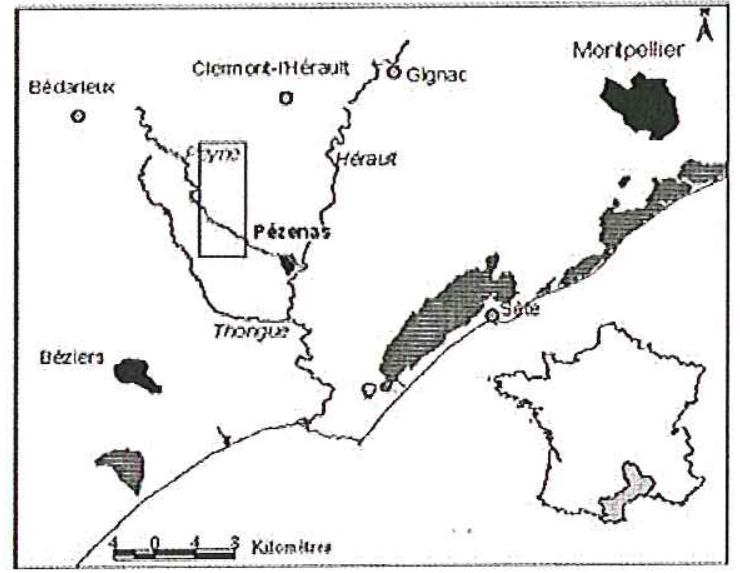

conditions (Fig. 8.2). They have produced an intricate soil pattern that includes a large range of soil types such as Calcaric, Chromic and Eutric Cambisols, Chromic and Eutric Luvisol and Eutric Fluvisols. Local transport of colluvial material along slopes added to the complexity of the soil pattern.

Fig. 8.2 Geology of the study area and the masked image showing only data on bare soil fields

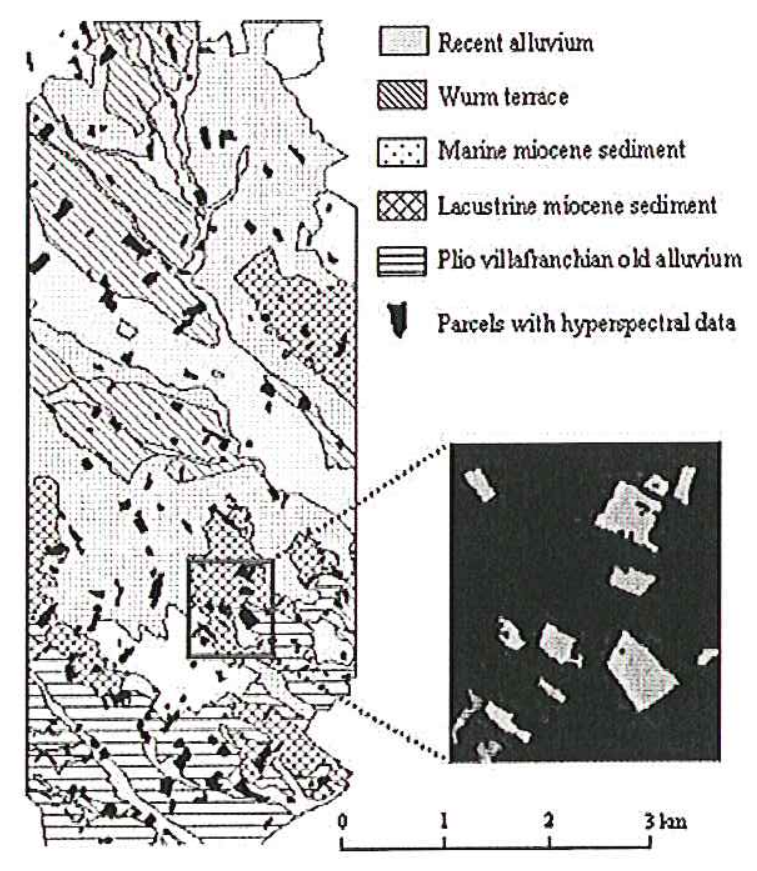




\subsubsection{The Hymap Image}

The HYMAP airborne imaging spectrometer measured reflected radiance in 126 non-contiguous bands covering the $400-2,500 \mathrm{~nm}$ spectral domain with around $19 \mathrm{~nm}$ bandwidths and average sampling intervals of $17 \mathrm{~nm}$ in the $1,950-2,480 \mathrm{~nm}$ domain. The HYMAP image was acquired on July 13th 2003 with a spatial resolution of $5 \times 5 \mathrm{~m}$. This image was geometrically, atmospherically and topographically corrected (see details in Lagacherie et al., 2008).

Living (essentially vineyard) and dry vegetation were masked on the HYMAP image using respectively the NDVI and the cellulose absorption band $(2,010 \mathrm{~nm})$. The final result was a masked image covering $23.5 \mathrm{~km}^{2}$ with data only on bare soil fields (Fig. 8.2).

\subsubsection{Field Data}

Clay and $\mathrm{CaCO}_{3}$ contents were selected as examples of target soil properties since they are widely used by soil surveyors to describe soil types and are essential to quantify the soil erodibility. These two properties were determined by routine soil analysis for 52 sites collected over bare soil fields. The sampling was designed to capture the variability of the propertics of interest within the study area (clay contents from 65 to $452 \mathrm{~g} / \mathrm{kg}$ and $\mathrm{CaCO}_{3}$ contents from 0 to $360 \mathrm{~g} / \mathrm{kg}$ ). Laboratory vis-NIR reflectance spectra were recorded for these 52 samples with an ASD pro FR Portable Spectro-radiometer, and field vis-NIR reflectance spectra were recorded for the 19 samples collected in 2005 with the same tool. Detailed measurement protocols are available in Lagacherie et al. (2008).

\subsubsection{Methods}

Two well-known techniques were used to infer the soil properties from laboratory and HYMAP spectra; the continuum removal analysis (CR) and the partial least square regression (PLSR).

$\mathrm{CR}$ is a means of normalizing reflectance spectra to allow comparison of individual absorption features from a common baseline (Clark and Roush, 1984). The CR technique presents the advantage of targeting specific absorption features that should be resistant across scales and observation conditions. After continuum removal, absorption band depth values are calculated from vis-NIR spectra to estimate mineral, rock, and soil properties. Specific absorption features of minerals, rocks, and soil properties, including clay and $\mathrm{CaCO}_{3}$, have been widely studied under laboratory conditions. The absorption band depth values at 2,206 and $2,341 \mathrm{~nm}$, calculated from laboratory spectra after continuum removal, can be used to estimate clay and $\mathrm{CaCO}_{3}$ content, respectively. 
PLSR is one of the most common multivariate statistical techniques for spectral calibration and prediction of soil properties (e.g., Viscarra Rossel et al., 2006). In the PLSR approach, the full spectrum is used to establish a linear regression model where the significant information contained in the vis-NIR spectra is concentrated in a few latent variables that are optimized to produce the best correlation with the desired property of interest.

\subsection{Results}

\subsubsection{How to Derive Soil Property Estimates from Vis-NIR Spectra? (Gomez et al., 2008a; Lagacherie et al., 2008)}

Table 8.1 shows the performance of the two tested methods for predicting clay and calcium carbonate content from laboratory and remote sensing (HYMAP) spectra. It shows that the two soil properties can be predicted with an acceptable precision although a decrease of precision is observed when passing from laboratory to HYMAP spectra. The PLSR technique performs better than the CR approach when the absorption peak selected in the CR approach corresponds to a chemical species that does not match perfectly the soil property of interest (e.g., $\mathrm{OH}^{-}$for clay content), or when applied to the lower quality spectra provided by an airborne sensor like HYMAP. In these situations, PLSR is able to find surrogate spectral features that retain satisfactory estimations of the studied soil properties. However, these surrogate spectral features correspond to soil properties that have only area-specific correlations with the soil property of interest (e.g., soil colour with clay content), or to chemical species that cannot be related with any explainable soil features. This means that extrapolations to larger pedological contexts must be envisaged with care (Gomez et al., 2008a). Conversely, in the case of $\mathrm{CaCO}_{3}$ estimations from laboratory spectra, CR overcame PLSR since it nearly equals the PLSR results while using a more parsimonious model. Although these results only concern two soil properties, this will certainly be extended in the near future to other soil properties that are known to be suitable for spectrometry analysis (granulometric fractions, carbon content, iron content, salinity, ...).

Table 8.1 Estimations of Clay and $\mathrm{CaCO}_{3}$ contents of soil surface from laboratory and HYMAP spectra using the continuum removal method and the PLSR regression (after Gomez et al., 2008a)

\begin{tabular}{|c|c|c|c|c|c|}
\hline & & \multicolumn{2}{|c|}{ Laboratory spectra } & \multicolumn{2}{|c|}{ HYMAP spectra } \\
\hline & & Clay & $\mathrm{CaCO}_{3}$ & Clay & $\mathrm{CaCO}_{3}$ \\
\hline $\mathrm{CR}$ & $R^{2}$ & 0.73 & 0.92 & 0.58 & 0.47 \\
\hline & RMSE (g/kg) & 44 & 52 & 82 & 132 \\
\hline PLSR & $\begin{array}{l}R^{2} \\
\text { RMSE }(\mathrm{g} / \mathrm{kg})\end{array}$ & $\begin{array}{l}0.85 \\
31\end{array}$ & $\begin{array}{l}0.94 \\
39\end{array}$ & $\begin{array}{l}0.64 \\
50\end{array}$ & $\begin{array}{l}0.77 \\
77\end{array}$ \\
\hline
\end{tabular}

Abbreviations: CR: continuum removal method, PLSR : partial least squares regression method, RMSE: root mean square error, $R^{2}$ : determination coefficient (obtained by cross-validation) 


\subsubsection{What Are the Main Perturbing Factors When Passing from Laboratory to Remote Sensing Spectra? (Lagacherie et al., 2008)}

Nine intermediate stages from the laboratory up to HYMAP sensor measurements were considered for separately evaluating the factors of confusion that may decrease the estimation performances when going across scales and sensors (Fig. 8.3). These stages were either characterised by additional measurements or by simulations (see details in Lagacherie et al., 2008). The importance of each factor of confusion was evaluated by examining the correlations between the soil property predictions using the CR method with data from the two corresponding consecutive measurement stages.

Results show that the main uncertainty factor in scaling up laboratory to airborne measurements is the capacity of airborne reflectance measurements to be spectrally consistent (good inter-band relative radiometric accuracy), and well corrected from atmospheric effects, particularly regarding water vapour (first line in Fig. 8.3). A small effect on the degradation of the radiometric performances was observed as well. The influence of pebbles was found generally limited except for $\mathrm{CaCO}_{3}$ estimates with calcareous pebbles and high $\mathrm{CaCO}_{3}$ contents. More sites

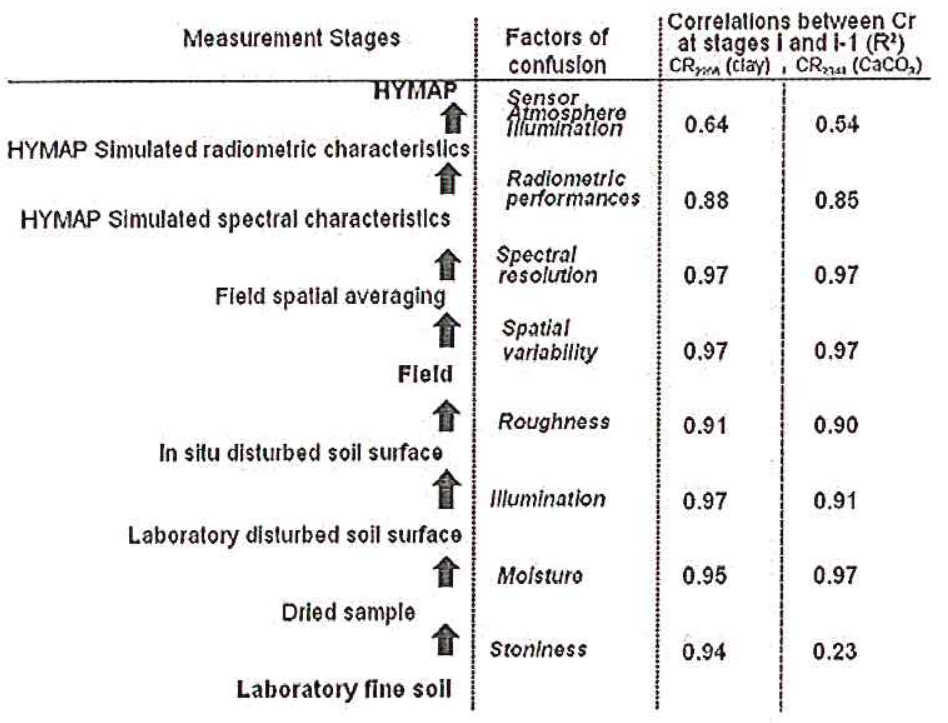

Fig. 8.3 The different possible factors of confusions across scale and sensors and their influence on soil property predictions. A low $R^{2}$ between consecutive stages means a strong influence of the corresponding confusion factor (after Lagacheric et al., 2008) 
will be necessary to identify situations where pebbles have to be taken into consideration. The other factors considered (i.e., spectral and spatial resolutions, surface roughness, illuminations conditions and soil moisture) played a minor role.

\subsubsection{How to Obtain a Digital Soil Map from a Hyperspectral Image Partly Covered by the Vegetation?}

An interpolation-aggregation procedure has been developed to derive a $100 \times 100 \mathrm{~m}$ resolution digital soil map of clay content of the entire study region from a hyperspectral image where pixels with vegetation cover were masked. In this situation, the source of data is the set of scattered bare soil fields with hyperspectral soil

Fig. 8.4 Map of the local means of clay content at the soil surface

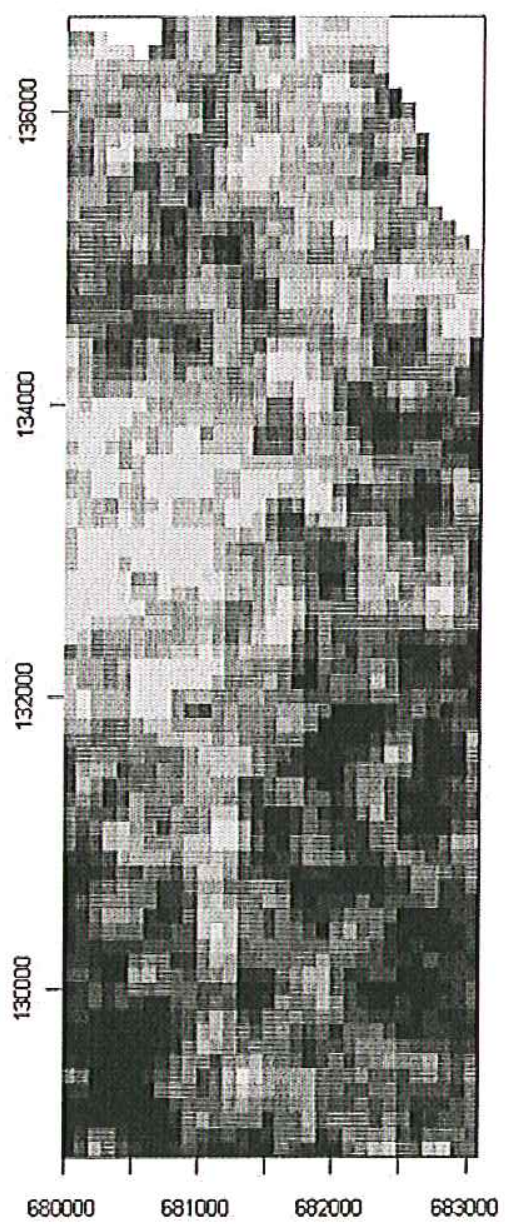


property estimations. The procedure includes two steps: (i) interpolation of the soil properties predicted from HYMAP spectra in the bare soil fields, and (ii) pooling of the interpolation outputs to obtain the soil pattern parameters (mean, variances and semi-variances at lags $0-50 \mathrm{~m}$ and $50-100 \mathrm{~m}$ ) of the pixels of the targeted digital soil map. A conditional simulation approach was selected as the interpolation function since it can predict the local values of the property of interest while giving a realistic representation of its spatial structure.

The procedure was applied using the absorption band depth values at 2,206 nm $\left(\mathrm{CR}_{2,206}\right)$ that satisfactorily mapped clay content of the soil surface in bare soil fields as input data (Table 8.1). A double-log transformation of $\mathrm{CR}_{2,206}$ was applied to obtain normal distributions. The conditional simulation was performed from the

a)

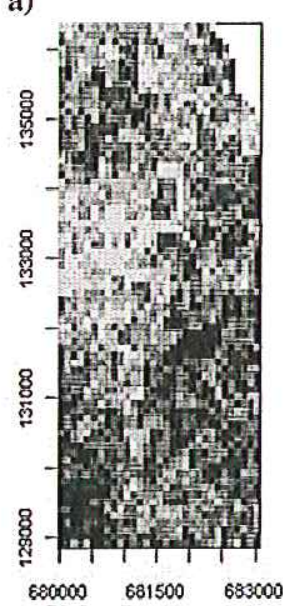

c)

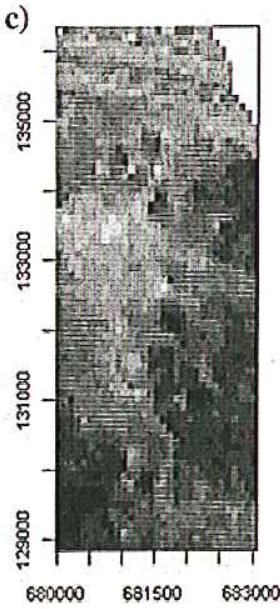

b)

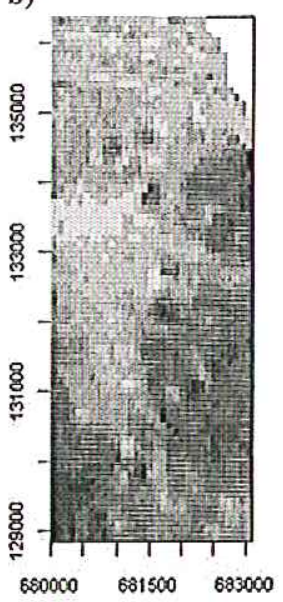

Fig. 8.5 Maps of the (a) local variances, (b) semi-variances at lag $0-50 \mathrm{~m}$ and $(\mathrm{c})$ semi-variances at lag $50-100 \mathrm{~m}$ 
variogram of the double-log transformed $\mathrm{CR}_{2,206}$ computed from the set of bare soil pixels with $\mathrm{CR}_{2,206}$ values. It was conditioned by bare soil pixels randomly sampled from this set. The Circulant Embedding (CE) simulation algorithm was selected for its ability of handling large datasets. Double log transformed outputs were finally back transformed into $\mathrm{CR}_{2,206}$ estimates and the linear formula calibrated by Lagacherie (2008) was applied to obtain clay content values (clay\% $=3,790^{*}$ $\left(1-\mathrm{CR}_{2,206}\right)$ ).

Figure 8.4 shows the map of local means of clay content at $100 \times 100 \mathrm{~m}$ resolution variances that were obtained from the interpolation-aggregation procedure, and Fig. 8.5 shows the corresponding maps of local variances and semi-variances. The spatial distribution of these two soil pattern parameters seems to be in relation with the geological pattern of the region shown in Fig. 8.2.

As validation was not possible on pixels directly, a cross validation procedure was performed from the set of bare soil parcels. It showed that local means were estimated with an acceptable accuracy $\left(R^{2}=0.62\right)$. The quality of estimations of the local variance and semi-variances was not so good $\left(R^{2}=0.30, R^{2}=0.29\right.$, $R^{2}=0.22$ for local variance, local semi-variance at lag $0-50 \mathrm{~m}$, local semi-variance at lag $50-100 \mathrm{~m}$, respectively) since the procedure failed to reproduce the small number of erratic large local variances and semi-variances that was observed in the study region. However, the part of the variation of local variance in relation with geological variations seemed to be correctly represented (Fig. 8.5).

\subsection{Conclusion}

The following conclusions can be drawn from the first results of the Peyne experiment:

- Satisfactory predictions of bare soil surface properties can be obtained from hyperspectral imagery, although a decrease of precision is observed when passing from laboratory to airborne reflectance spectra.

- Calibration uncertainty of the airborne sensor and non-corrected atmospheric effects are by far the main factors that explain this decrease of precision.

- A digital soil map at medium resolution $(100 \times 100 \mathrm{~m})$ can be derived from a hyperspectral image with part of the pixels covered by vegetation.

In the near future, a proof-of-concept zone located in the gouvernorat of Nabeul (northern Tunisia) will be implemented. It is expected to demonstrate that a digital soil map of the Mediterranean areas that fit the standards of the GlobalSoilMap.net project (see Chapter 33) can be produced using hyperspectral imagery associated with digital terrain model and legacy soil data. The added value of this digital soil map will be evaluated for the spatial assessment of soil vulnerability to erosion and the mapping wheat yield in water limited situations. 


\section{References}

Ben-Dor, E., Taylor, R.G., Hill, J., Demattê, J.A.M., Whiting, M.L., Chabrillat, S., and Sommer, S., 2008. Imaging spectrometry for soil applications. Advances in Agronomy 97:321-392.

Clark, R.N., and Roush, T.L., 1984. Reflectance spectroscopy: quantitative analysis techniques for remote sensing applications. Journal of Geophysical Research 89:6329-6340.

Gomez, C., Lagacherie, P., and Coulouma, G., 2008a. Continuum removal versus PLSR method for clay and calcium carbonate content estimation from laboratory and airborne hyperspectral measurements. Geoderma 148(2):141-148.

Gomez, C., Viscarra Rossel, R.A., and McBratıey, A.B., 2008b. Soil organic carbon prediction by hyperspectral remote sensing and field vis-NIR spectroscopy: an Australian case study. Geoderma 146:403-411.

Lagacherie, P., 2008. Digital soil mapping: a state of the art. In: Hartemink A., McBratney, A.B., and Mendonça-Santos, L. (eds.), Digital Soil Mapping with Limited Soil Data. Springer, Dordrecht.

Lagacherie, P., Baret, F., Feret, J.B., Madeira Netto, J.S., and Robbez-Masson J.M., 2008. Clay and Calcium carbonate contents estimated from continuum removal indices derived from laboratory, field and airborne hyper-spectral measurements. Remote Sensing of Environment 112:825-835

Madeira Netto, J.S., Robbez-Masson, J.-M., and Martins, E., 2007. Chapter 17. Visible-NIR hyperspectal imagery for discriminating soil types in the la Peyne watershed, France, pp. 219-234. In: Lagacherie, P., McBratney, A.B., and Voltz, M. (eds.), Digital Soil Mapping, An Introductory Perspective. Developments in Soil Science, vol. 31. Elsevier, Amsterdam.

Viscarra Rossel, R.A., Walwoort, D.J.J., Mc Bratney, A.B., Janik, L.K., and Skjemstad, J.O., 2006. Visible, near infrared, mid-infrared or combined diffuse reflectance spectroscopy for simultaneous assessment of various soil properties. Geoderma 131:59-75. 
Janis L. Boettinger - David W. Howell ·

Amanda C. Moore - Alfred E. Hartemink .

Suzann Kienast-Brown

Editors

\section{Digital Soil Mapping}

Bridging Research, Environmental

Application, and Operation

黛 Springer 
Editors

Dr. Janis L. Boettinger

Utah State University

Dept. Plants, Soils, \&

Climate

4820 Old Main Hill

Logan, UT 84322-4820

USA

janis.boettinger@usu.edu

Amanda C. Moore

U.S. Department of Agriculture

Natural Resources Conservation

Service

339 Busch's Frontage Road

Suite 301

Annapolis, MD 21409

USA

amanda.moore@md.usda.gov

Suzann Kienast-Brown

U.S. Department of Agriculture

Natural Resources Conservation

Service

Utah State University

Dept. Plants, Soils, \&

Climate

4820 Old Main Hill

Logan, UT 84322-4820

USA

suzann.kienast@ut.usda.gov
David W. Howell

U.S. Department of Agriculture

Natural Resources Conservation

Service (Retired)

P.O. Box 709

Arcata, California 95518

USA

david@earthmapphoto.com

Prof. Dr. Alfred E. Hartemink

International Soil Reference

Information Centre (ISRIC)

Wageningen

Netherlands

Alfred.Hartemink@wur.nl

ISBN 978-90-481-8862-8

e-ISBN 978-90-481-8863-5

DOI 10.1007/978-90-481-8863-5

Springer Dordrecht Heidelberg London New York

Library of Congress Control Number: 2010925363

(C) Springer Science+Business Media B.V. 2010

No part of this work may be reproduced, stored in a retrieval system, or transmitted in any form or by any means, electronic, mechanical, photocopying, microfilming, recording or otherwise, without written permission from the Publisher, with the exception of any material supplied specifically for the purpose of being entered and executed on a computer system, for exclusive use by the purchaser of the work.

Cover image: Digital soil map illustrating the distribution of 24 soil classes in the Big Wash watershed in the Great Basin region of southwestern Utah, USA (adapted from Figure 15.2b, Chapter 15 from this book).

Printed on acid-free paper

Springer is part of Springer Science+Business Media (www.springer.com) 